\title{
La reconversión industrial en El Salvador y la necesidad de una política sectorial estratégica que le de dirección al proceso
}

\author{
Francisco Sorto
}

\section{1. ¿Qué es la reconversión Industrlal?}

Según Eduardo Doryan Garrón, ex-Ministro de Ciencia y Tecnologia de Costa Rica y experto en la maleria I"la reconversión industrial es una acción articulada de la sociedad y der Estado en respuesla a un rezago imporlante del sector manufacturero ante el mercado internacional, ante un "shock" externo, o ante un cambio de política sustancial tendiente a modificar la estrategia de desarrollo de un pais". Adicionalmente sostiene que, ante este tipo de evenlos, existen dos caminos: a) dejar que las mismas empresas se ajuslen por si mismas, ignorando los costos, así como la resislencia social y política de los sectores afectados, o, b) generar acciones que faciliten el ajuste, promuevan el diálogo entre los sectores involucrados, revitalicen los sectores viables de proseguir operando compelitivamenle y calalicen el desarrollo de nuevas actividades productivas'.

La literatura sobre reconversión industrial proviene principalmente de los Estados Unidos, donde la penetración de sus mercados por parte de Japón y de Corea, entre otros paises, ha venido desplazando una parte importante de la industria local, generando asi marcadas tendencias ha-

1. Dóryan Garrón, Eduardo-Entendiendo la Reconversión Industrial. Nola técnica sin número, INCAE, Costa Rica, 1990. 
cia la tercialización de la economía, con lo cual los Estados Unidos han perdido lerreno en la hegemonia lecnológica mundial, reduciéndosele el potencial de crecimiento en ciertas industrias de alto valor agregado o en industrias de punla. ${ }^{2}$

Debido a la preocupación que dicho fenómeno despertó en el gobierno, se formó una comisión a nivel presidencial para detectar cuáles eran los origenes de los problemas que experimentaba la industria; los resullados de los estudios mostraban que algunas de las llaves del éxito productivo de una economía dependian de la calidad de su educación, de la eficiencia de los servicios públicos prestados, de la cohesión social existente, del grado de competencia interna y de la armonia entre la estrategia empresarial y la politica macroeconómica del gobierno. -

A partir de los resultados anteriores, muchos expertos han contribuido en la tormulación de complejas estrategias de reconversión industrial para recuperar la competilividad perdida; es oportuno sefialar aqui, que la implemenlación de un programa de reconversión industrial es más necesario en una economía que ha estado inmersa dentro de regímenes proscriplivos, ${ }^{3}$ como los observados en América Latina en las décadas pasadas.

La reconversión induslrial es un proceso permanente de reorientación de la capacidad producliva de un pais, en función de los precios relativos de los bienes y servicios demandados por los consumidores efectivos; por medio de la reconversión induslrial se busca mejorar la asignación de los recursos productivos, por lo tanto, dicho proceso contempla no sólo la transformación de los parques industriales, sino que la mentalidad misma de los empresarios, en cuanto al desarrollo de una visión estralégica de mediano plazo, libre de las distorsiones provocadas por políticas proteccionistas. .

\section{2. ¿Cómo debe verse la reconversión Industrlal en EI Salvador?}

Para analizar adecuadamenle la reconversión industrial en El Salvador, conviene hacerlo desde la perspectiva del actual programa de Ajuste Estruclural, como consecuencia del cambio en la orientación de la política económica manejada por el Eslado, la cual esta empentada en ampliar la apertura comercial y financiera del país con el exterior; a dilerencia de

2. Buitelart, Rudolf M. -Elementos Básicos de un Proceso de Reconversión Indusirial: Aspectos Teóricos y Prácticos, Conterencia Pronunciada durante el VII Congreso de Profesionales en Ciencias Económicas, Agoslo 1991.

3. Bhagwati, Jagdish-Economla Proleccionista, Germika, México 1990. 
la política proteccionista implementada en la región en las últimas décadas; a raiz de ese giro, las industrias locales se verán obligadas a tomar las providencias del caso para trabajar bajo condiciones más competitivas; sin embargo, independientemente del programa de Ajuste Estructural ensayado en El Salvador; la reconversión es una necesidad impuesta por las cambianles condiciones del entorno económico internacional, que exige la modernización permanenle de los parques industriales y una mayor incorporación tecnológica en las actividades produclivas; so pena de perder participación en el mercado mundial o de experimenlar un proceso de desindusırialización gradual, ante la incapacidad de competir con lécnicas de producción más eficientes.

- La implementación de un programa de Ajuste Estruclural obliga a modificar los procesos productivos de lodas las actividades económicas que se ven expuestas a una mayor competencia externa, ya que al eliminarse las barreras comerciales que les garantizaban a las empresas domésticas un mercado inlerno caulivo, éstas se ven forzadas a desarrollar venlajas comparativas reales; cuando se habla de reconversión industrial tiende a pensarse que las únicas ramas que deben modernizarse son las del sector industrial, sin embargo, cualquier actividad que haya experimentado un incremento en la competencia interna debe reconvertirse, entendiendo por ésto la incorporación tecnológica necesaria para sobrevivir y crecer dentro de un mercado más dinámico. -

\section{3. ¿Es necesarla una politlca sectorlal y comerclal estratéglca para el éxito de la reconversión productlva?}

Algunos renombrados economislas soslienen que hacer política comercial e industrial estralégica carece de sentido en una economía pequeña, dadas las acluales condiciones del comercio internacional, donde las ventajas comparativas han sido superadas por medio del avance tecnológico ${ }^{4}$ y donde la abundancia de recursos naturales y humanos ha perdido importancia en la eslruclura de costos de los bienes manufacturados; sin embargo, dejar que el entorno moldee por completo la estruclura productiva de un pais, denota carencia total de interés estatal para garantizar un minimo de eslabilidad productiva local; tal displicencia sólo logra aumenlar la vulnerabilidad de una economia a los vaivenes del entorno económico internacional e impedir el desarrollo equilibrado y sostenido de la misma.

4. Brander, James A. - Art. Rationales tor Strategic Trade and Industrial Policy, Lib. Strategic Trade Policy and the New Internacional Economics, editado por Paul R. Krugman, 1988. 
Es irresponsabilidad de un gobierno privar a su pais de la oportunidad de transitar ordenadamente de una economía protegida a una economía abierta, por lal motivo es necesaria la formulación de una política seclorial estralégica, de la cual lorme parte la política de reconversión integral de la economía y en esta última, la reconversión industrial.

En El Salvador poco se ha avanzado en el diseño de una política de reconversión industrial y casi nada, por no decir nada, en la formulación de una política de desarrollo sectorial; la apertura comercial producida por el programa de Ajuste Estructural ha obligado a muchas empresas, principalmente grandes, a realizar esfuerzos de reconversión sin mayor respaldo estatal.

Hasla este momento lo único que ha hecho el gobierno para definir una política industrial nacional, es contratar con fondos del PNUDCEPAL-ILPES a consultores independientes para que elaboren un documento sobre el problema, el cual fue presentado por el Ministerio de Economla en Marzo de 1991.

El documento elaborado por el Ministerio de Economia, es un borrador para generar discusión y no constituye la posición oficial sobre cuál será su politica estratégica de reconversión industrial; en la introducción del mismo puede leerse lo siguienle: "Este documento tiene el propósito de servir como instrumenlo básico para la discusión con los diferentes agentes económicos y sociales e instituciones involucradas en el proceso de desarrollo industrial de nuestro pais. O sea, tiene un sentido esencialmente motivador para la participación de grupos o personas interesadas en el quehacer económico y que puedan aportar, al tema de la reconversión y desarrolio de la industria nacional, sus conocimientos y experiencias para lograr una mejor precisión en la delinición y ejecución de la política industrial y el programa de reconversión". 5

Es importante involucrar a todos los seclores económicos en la tarea de la transformación productiva del país; sin embargo, el gobierno tiene la obligación de definir una política industrial básica que permita a dichos seclores adaptarse mejor a las condiciones del entorno económico interno y externo; no se debe esperar que la politica industrial surja espontáneamente de la discusión de la problemática.

A pesar de la indefinición del documento en cuanlo a la polílica industrial del gobierno, éste resulta valioso porque senala algunos elementos

5. MINISTERIO DE ECONOMIA - Dirección de Promoción y Desarrollo Industrial- BASES PARA LA FORMULACION DE LA POLITICA INDUSTRIAL $Y$ PROGRAMA DE RECONVERSION INDUSTRIAL EN EL SALVADOR, Marzo 1991. 
básicos que deben tenerse presentes en el diseño e implementación de dicha política; se reconoce la necesidad de una política industrial y tecnológica que incluya, entre olros: un programa de reconversión industrial, acciones de apoyo a la promoción de exportaciones, programas de mejoramiento de la intraestructura básica, una política de ciencia y lecnología, programas de apoyo a la pequefía y mediana empresa, el mejoramienlo de la intermediación financiera y el tortalecimiento de los mercados de capital y una polílica clara de promoción de nuevas inversiones.

Como extensión nalural de lo anterior, se destaca la urgencia de replantear la estralegia de crecimiento e industrialización, basándola en nuevos parámetros de eficiencia y de competitividad internacional; asimismo, debe definirse una política comercial con una nueva concepción sobre la integración regional, lomando en cuenta el grado de complementariedad de los países del área, asi como la posibilidad de realizar un esfuerzo coordinado para el desarrollo de nuevos mercados y el máximo aprovechamiento de los acuerdos comerciales multilalerales.

Por otra parte, el sector privado ha realizado esfuerzos propios orienlados a delinear una estrategia con la cual entrentar, en el campo de balalla de la productividad, la mayor competencia externa ligada a la apertura comercial derivada del Ajusle Estruclural; asi tenemos que, en Julio de 1991 la Asociación Salvadoreńa de Industriales, elaboró un diagnóstico sectorial del ramo, tipilicando las áreas funcionales de $403 \mathrm{em}$ presas agrupadas según la clasificación CIIU*, en nueve ramas.

Debido a la ausencia de una polílica industrial en el pais, la gran empresa ha tenido que ir adivinando hacia donde debe dirigir sus inversiones en materia de reconversión, solicitándole al gobierno muchas veces medidas defensivas temporales para amortiguar los coslos relacionados a la modernización de sus plantas: sin embargo, gran parte de la pequena empresa se encuentra al margen de la asistencia financiera para la reconversión y ni siquiera son tomados en cuenla por las grandes gremiales, al disefiar sus programas de translormación productiva seclorial.

Las áreas esludiadas fueron: Area Organizaliva, Producción, Mercadeo y Ventas, Exportaciones, Financiera y de Personal; se resalta la necesidad de la reconversión en el sector, se enumeran los factores que afectan el desarrollo de la industria y las variables de ajuste necesarias para lograr una mayor eficiencia producliva.

6. Asociación Salvadoreña de Industriales-Diagnóstico Sectorial de la Industria Manulacturera, Julio 1991. 
En este diagnóstico como en el documento preparado por el Ministerio de Economia, se destaca la imporlancia del sistema financiero en el éxito del proceso de reconversión industrial; sin embargo, su importancia sólo se enfoca desde el punto de visla del tinanciamienlo.

Es ese mismo sentido, el 29 de Agosto de 1991 se inauguró el VII Congreso de Profesionales en Ciencias Económicas, teniendo como tema central del evento la reconversión; el congreso contó con invitados extranjeros que destacaron la importancia de ésta en la estrategia de crecimiento sostenido de Chile y Costa Rica.'

Dentro de la genda de discusión del congreso, fueron abordados algunos temas relacionados con el Financiamiento a la Reconversión Industrial, el Mercado Bursátil y la Reconversión Industrial y las Relormas EsIructurales en el Sector Industrial; asimismo, se disculió la importancia que tiene sincronizar la reconversión integral de la economía con la modernización del sislema linanciero, debido al apoyo que debe brindar a los estuerzos de incorporación tecnológica sectorial y para facilitar su adaplación a un escenario más competitivo.

La Comisión económica para América Lalina y el Caribe ha mantenido en los últimos anos una fuerte asistencia técnica en maleria de reconversión industrial para los países centroamericanos; el 8 de Octubre de 1990 con recursos del PNUD (Programa de las Naciones Unidas para el Desarrollo) publicó un estudio sobre reconversión industrial en Centroamérica y el 19 de Diciembre del mismo año, publicó un informe sobre talleres de reconversión industrial para el área. ${ }^{8}$

Además, dicho organismo ha publicado una serie de diagnósticos por ramas industriales con allas probabilidades de reconvertirse, tales como el caso de la indusiria textil y del calzado; sin embargo, el diseño de una política industrial nacional es responsabilidad de las autoridades económicas de cada país y es en este punto donde no se ha avanzado mucho en El Salvador.

Los esfuerzos más visibles realizados por el gobierno para acompanar el desmantelamiento de las barreras comerciales y las distorsiones en los precios relativos locales, se encuentran en la separación de fon-

7. Motles Glisser, Isaac-Conterencia sobre: Una Visión Empresarial de la Experiencia Chilena en la Transformación del Sector Textil, VIII Congreso de Protesionales en Ciencias Económicas, Agosio 1991.

8. CEPAL-RECONVERSION INDUSTRIAL EN CENTROAMERICA, LC/G. 1640. Octubre 8 1990; Informe de los Talleres de Reconversión Industrial en Costa Rica, El Salvador, Gualemala, Honduras y Nicaragua, LC/MEX/L. 149, Dic. 191990. 
dos prestables destinados al financiamiento de proyectos de reconversión; pero antes de separar londos para el proceso, es fundamental evaluar la capacidad de reconversión de cada actividad en general y de cada rama industrial en particular; la asistencia financiera indiscriminada en apoyo de todos los sectores afectados por la mayor apertura comercial puede ser desastrosa, ya que pueden estarse asignando recursos a industrias que ya superaron su etapa de maduración y que lienen pocas oportunidades de sobrevivencia en un mercado más hostil; es necesario por to tanlo el establecimiento de una política industrial clara por parte del gobierno, que permita administrar eficientemente la cartera de préstamos del sistema financiero; en caso contrario el sislema bancario podria no recuperar fondos olorgados a empresas sin viabilidad financiera dentro de un mercado más abierlo.

Es fundamental contar con sulicientes recursos para financiar la reconversión industrial; pero tal premisa no es suliciente para garantizar el éxito de la translormación productiva de la economia, máxime cuando se ha efecluado la desgravación arancelaria más aceleradamente de lo acordado; el 6 de enero del corriente año se efectuó la última modificación a los aranceles, bajando el lecho del $30 \%$ vigente desde el 5 de Junio de 1991, al 20\%, a excepción de algunas partidas constituidas por textiles y calzado.

Los pasos que se han dado en materia de reconversión apuntan principalmente a la modernización del parque industrial, por medio de la reposición de equipo, adquisición de maquinaria moderna y la ampliación de planlas; se ha relegado a planos secundarios la inversión en capital humano y la incorporación tecnológica y de conocimientos.

Se ha malentendido lo que es la reconversión industrial, menospreciando los beneficios que se pueden lograr en eliciencia por medio de una mejor organización, de la conformación de un equipo ejecutivo dinámico y de la ejecución de proyectos.

\section{Conclusiones}

Debido a las cambiantes condiciones del enlorno económico mundial, y como resultado de la puesta en marcha de un programa de liberalización económica en el país, se hace necesaria la implementación de un programa de reconversión industrial, que involucra a lodos aquellos sectores que se vean afectados por el aumento de la competencia externa.

Para que dicha Iranslormación sea exitosa y se reduzcan al mínimo posible los costos de la transición, es necesario que el Estado delina una 
política estratégica que oriente al sector privado sobre la dirección que debe darle a sus inversiones; en caso contrario la economia se ajustaría automáticamente y desordenadamenle, con elevados costos económicos y sociales para el pais. No obstante el eslado final de la producción nacional no seria eslable. 